\title{
Bandgap Engineering in ZnO By Doping with 3d Transition Metal Ions
}

\author{
D. Paul Joseph ${ }^{1,2}$ and C. Venkateswaran ${ }^{1}$ \\ ${ }^{1}$ Materials Science Centre, Department of Nuclear Physics, University of Madras, Guindy Campus, Chennai 600025, India \\ ${ }^{2}$ Center for Condensed Matter Sciences, National Taiwan University, Taipei 10617, Taiwan
}

Correspondence should be addressed to C. Venkateswaran, cvunom@hotmail.com

Received 6 November 2010; Accepted 21 February 2011

Academic Editor: Robert Moshammer

Copyright ( 2011 D. P. Joseph and C. Venkateswaran. This is an open access article distributed under the Creative Commons Attribution License, which permits unrestricted use, distribution, and reproduction in any medium, provided the original work is properly cited.

Bulk $\mathrm{Zn}_{0.95} \mathrm{TM}_{0.05} \mathrm{O}(\mathrm{TM}=\mathrm{Cr}, \mathrm{Mn}, \mathrm{Fe}, \mathrm{Co}$, and $\mathrm{Ni}$ ) were synthesized by the standard ceramic method and explored for variation in their band gap energies using Diffuse Reflectance Spectroscopy in the ultraviolet-visible region. Phase quantification and compositional studies were performed using Rietveld analysis of the X-Ray Diffraction patterns, Scanning Electron microscopy, and Energy Dispersive X-Ray Analysis. Due to 3d transition ion doping, the samples have brilliant colors, and the absorption edge of $\mathrm{Zn}_{0.95} \mathrm{TM}_{0.05} \mathrm{O}$ was found to shift towards the visible and ultraviolet-visible region. The blue and red shifts in band gaps observed for various transition metal ion-doped $\mathrm{ZnO}$ are discussed.

\section{Introduction}

Zinc Oxide $(\mathrm{ZnO})$, a direct wideband gap semiconductor, has been of great interest for application in optical devices such as blue-violet and UV-light emitting diodes and laser diodes $[1,2]$. Recently, $\mathrm{ZnO}$ is alloyed with various " $3 \mathrm{~d}$ " transition metal (TM) ion for exploring its applicability in the field of SPINTRONICS (Spin Transport Electronics) [3-7]. Theoretical simulation of electronic structures of $3 \mathrm{~d}$ transition metal ion- doped $\mathrm{ZnO}$ has been reported by Toyoda et al. [8]. The ferromagnetic behavior and high transition temperature of the wide band gap semiconductors have wide controversy. Theory of spinodal decomposition for the observed magnetic behavior in wide band gap semiconductors has been framed recently by abinitio electronic structure calculations [9-11]. Owing to the transparency of $\mathrm{ZnO}$, "transparent magnets" [4] exhibiting a number of unique magnetic, magneto-optical, and magnetotransport properties are also expected. Oxide-based Diluted Magnetic Semiconductors (DMSs) are superior to their III-V counterparts, and a number of review articles were published on them [12-15]. To exploit materials for optoelectronic applications, it is essential to tune the optical band gap which can be done by way of doping with various " $3 \mathrm{~d}$ " transition metal ions apart from introducing spin degree of freedom into the $\mathrm{ZnO}$ matrix. Band gap tailoring at the ultraviolet end and visible region of the solar spectrum is of considerable interest for large area optical coatings. As most of the optical studies on ZnO DMS were on thin films only, the present study is aimed at measuring directly the band gap energies of bulk $\mathrm{Zn}_{0.95} \mathrm{TM}_{0.05} \mathrm{O}$ ( $\mathrm{TM}=\mathrm{Cr}, \mathrm{Mn}, \mathrm{Fe}, \mathrm{Co}$, \& Ni) using Diffuse Reflectance Spectrocopy (DRS) which is particularly suitable for the determination of absorption edges of powdered materials. Bulk $\mathrm{Zn}_{0.95} \mathrm{TM}_{0.05} \mathrm{O}(\mathrm{TM}=\mathrm{Cr}$, $\mathrm{Mn}, \mathrm{Fe}, \mathrm{Co} \& \mathrm{Ni}$ ) prepared by ceramic method were explored for their structural, compositional, and optical properties.

\section{Sample Preparation}

We adopted the standard ceramic method for the preparation of bulk samples of $\mathrm{Zn}_{0.95} \mathrm{TM}_{0.05} \mathrm{O}$ ( $\mathrm{TM}=\mathrm{Cr}, \mathrm{Mn}, \mathrm{Fe}, \mathrm{Co}$, $\& \mathrm{Ni}$ ) from high pure starting materials. The stoichiometric mixture for the composition $\mathrm{Zn}_{0.95} \mathrm{TM}_{0.05} \mathrm{O}$ ( $\mathrm{TM}=\mathrm{Cr}, \mathrm{Mn}$, $\mathrm{Fe}, \mathrm{Co}, \& \mathrm{Ni}$ ) was separately weighed and mixed manually (for $10 \mathrm{~h}$ ) in the presence of volatile acetone/isopropyl alcohol medium in an agate pestle and mortar to achieve homogenized mixture of the solid state reactants. 
TABLE 1: Details of Starting materials, processing temperatures, composition, and refined lattice constants of the bulk $\mathrm{Zn}_{0.95} \mathrm{TM}_{0.05} \mathrm{O}(\mathrm{TM}=$ $\mathrm{Cr}, \mathrm{Mn}, \mathrm{Fe}, \mathrm{Co}, \& \mathrm{Ni}$ ) samples.

\begin{tabular}{|c|c|c|c|c|c|c|}
\hline Sample ID & Starting materials & Sintering Temp & $\begin{array}{l}\% \text { of dopant } \\
\text { from EDAX }\end{array}$ & $\begin{array}{c}\text { Goodness of } \\
\text { fit }\end{array}$ & Wt $\%$ of secondary phases & $\begin{array}{c}\text { Refined lattice } \\
\text { parameters }\end{array}$ \\
\hline \multirow{2}{*}{$\mathrm{ZnO}$} & \multirow{2}{*}{ bulk $\mathrm{ZnO}$} & \multirow{2}{*}{ As obtained } & \multirow{2}{*}{ - } & \multirow{2}{*}{1.11} & \multirow{2}{*}{ Single phase } & $a=3.2753(2)$ \\
\hline & & & & & & $c=5.2476(4)$ \\
\hline \multirow{2}{*}{$\mathrm{Zn}_{0.95} \mathrm{Cr}_{0.05} \mathrm{O}$} & \multirow{2}{*}{$\mathrm{ZnO} \& \mathrm{Cr}_{2} \mathrm{O}_{3}$} & \multirow{2}{*}{$800^{\circ} \mathrm{C} / 24 \mathrm{~h}$} & \multirow{2}{*}{$6.31 \%$} & \multirow{2}{*}{1.53} & \multirow{2}{*}{$0.044 \%$ of $\mathrm{ZnCr}_{2} \mathrm{O}_{4}$} & $a=3.2647(2)$ \\
\hline & & & & & & $c=5.2283(4)$ \\
\hline \multirow{2}{*}{$\mathrm{Zn}_{0.95} \mathrm{Mn}_{0.05} \mathrm{O}$} & \multirow{2}{*}{$\mathrm{ZnO} \& \mathrm{MnO}$} & \multirow{2}{*}{$1200^{\circ} \mathrm{C} / 12 \mathrm{~h}$} & \multirow{2}{*}{$3.98 \%$} & \multirow{2}{*}{1.15} & \multirow{2}{*}{ Single phase } & $a=3.2800(2)$ \\
\hline & & & & & & $c=5.2514(5)$ \\
\hline \multirow{2}{*}{$\mathrm{Zn}_{0.95} \mathrm{Fe}_{0.05} \mathrm{O}$} & \multirow{2}{*}{$\mathrm{ZnO} \& \mathrm{Fe}_{2} \mathrm{O}_{3}$} & \multirow{2}{*}{$1200^{\circ} \mathrm{C} / 24 \mathrm{~h}$} & \multirow{2}{*}{$3.50 \%$} & \multirow{2}{*}{1.27} & \multirow{2}{*}{$0.022 \%$ of $\mathrm{Zn}_{0.98} \mathrm{Fe}_{2.02} \mathrm{O}_{4}$} & $a=3.2750(3)$ \\
\hline & & & & & & $c=5.2444(5)$ \\
\hline \multirow{2}{*}{$\mathrm{Zn}_{0.95} \mathrm{Co}_{0.05} \mathrm{O}$} & \multirow{2}{*}{$\mathrm{ZnO} \& \mathrm{Co}_{3} \mathrm{O}_{4}$} & \multirow{2}{*}{$900^{\circ} \mathrm{C} / 12 \mathrm{~h}$} & \multirow{2}{*}{$3.82 \%$} & \multirow{2}{*}{1.14} & \multirow{2}{*}{ Single phase } & $a=3.2607(2)$ \\
\hline & & & & & & $c=5.2200(5)$ \\
\hline \multirow[t]{2}{*}{$\mathrm{Zn}_{0.95} \mathrm{Ni}_{0.05} \mathrm{O}$} & \multirow[t]{2}{*}{$\mathrm{ZnO} \& \mathrm{NiO}$} & \multirow[t]{2}{*}{$1200^{\circ} \mathrm{C} / 24 \mathrm{~h}$} & \multirow[t]{2}{*}{$3.86 \%$} & \multirow{2}{*}{1.28} & \multirow{2}{*}{$0.0472 \%$ of $\mathrm{NiO}$} & $a=3.2717(1)$ \\
\hline & & & & & & $c=5.2376(3)$ \\
\hline
\end{tabular}

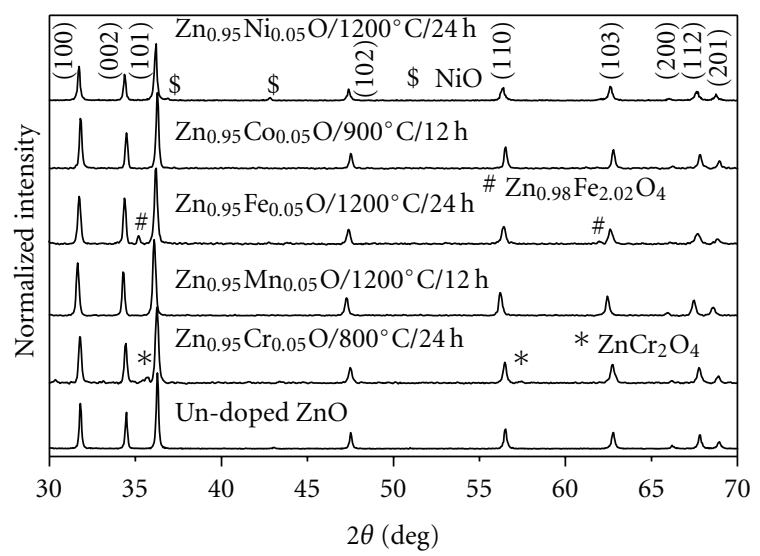

Figure 1: XRD patterns of bulk $\mathrm{Zn}_{0.95} \mathrm{TM}_{0.05} \mathrm{O}(\mathrm{TM}=\mathrm{Cr}, \mathrm{Mn}, \mathrm{Fe}$, Co, \& Ni) samples.

The surface area of reacting solids has a great influence on reaction rates; hence the area of contact between the reactants was increased by pressing the reacting powder into pellets. The green pellets were then placed over fresh alumina tray and sintered separately at various temperatures in air for various durations to attain single phase, with intermediate grindings. $\mathrm{Zn}_{0.95} \mathrm{Cr}_{0.05} \mathrm{O}$ samples were sintered using a gold foil placed over an alumina tray since $\mathrm{Cr}_{2} \mathrm{O}_{3}$ readily reacts with $\mathrm{Al}_{2} \mathrm{O}_{3}$ at high temperatures. The details of preparation of bulk $\mathrm{Zn}_{0.95} \mathrm{TM}_{0.05} \mathrm{O}$ ( $\mathrm{TM}=\mathrm{Cr}, \mathrm{Mn}, \mathrm{Fe}, \mathrm{Co}, \& \mathrm{Ni}$ ) samples are given in Table 1 .

\section{Results and Discussion}

The X-Ray Diffraction (XRD) patterns of $\mathrm{Zn}_{0.95} \mathrm{TM}_{0.05} \mathrm{O}$ ( $\mathrm{TM}=\mathrm{Cr}, \mathrm{Mn}, \mathrm{Fe}, \mathrm{Co}, \& \mathrm{Ni}$ ) are shown in Figure 1. Though the dopants and the host cation elements belong to the same $3 \mathrm{~d}$ series, only $\mathrm{Mn}$ and Co have the highest solubility in $\mathrm{ZnO}$ and form single phase. The other three dopants, $\mathrm{Cr}$, $\mathrm{Fe}$, and $\mathrm{Ni}$, do not form single phase with $\mathrm{ZnO}$ even after repeated trials by optimizing the processing temperatures and duration. Their solubility in $\mathrm{ZnO}$ is less, and the traces of formed secondary phases are listed in Table 1. Presence of $\mathrm{ZnCr}_{2} \mathrm{O}_{4}$ (Zincochromite), $\mathrm{Zn}_{0.98} \mathrm{Fe}_{2.02} \mathrm{O}_{4}$ (Franklinite) and $\mathrm{NiO}$ has been confirmed in the bulk $\mathrm{Cr}, \mathrm{Fe}$, and Ni doped $\mathrm{ZnO}$, respectively. Phase quantification was done using the program MAUD [16], which combines the Rietveld method and Fourier transform analysis. The estimated percentage of secondary phases for $\mathrm{Cr}, \mathrm{Fe}$, and $\mathrm{Ni}$ doped $\mathrm{ZnO}$ and the refined lattice parameters for $\mathrm{Zn}_{0.95} \mathrm{TM}_{0.05} \mathrm{O}(\mathrm{TM}=\mathrm{Cr}, \mathrm{Mn}$, $\mathrm{Fe}, \mathrm{Co}, \& \mathrm{Ni}$ ) samples are shown in Table 1 [17].

The Energy Dispersive X-Ray Analysis (EDAX) results shown in Figure 2 indicate that all the samples have a nominal variation in composition, which is attributed to the random substitution of the magnetic dopants at the cationic site. The Scanning Electron Microscope (SEM) images show aggregates of micron-sized particles (Figure 3 ). Since the ceramic method involves sintering of the stoichiometric mixtures at high temperatures, the crystallites are in the order of micrometer with relatively smooth surface. The aggregate of crystallites of various sizes indicating a size distribution is also clearly evident in the micrographs. The variation in size of the particles among the different $\mathrm{Zn}_{0.95} \mathrm{TM}_{0.05} \mathrm{O}$ (TM $=\mathrm{Cr}, \mathrm{Mn}, \mathrm{Fe}, \mathrm{Co}, \& \mathrm{Ni}$ ) samples is due to the difference in processing temperatures. Interested readers may refer to detailed structural and magnetic aspects of some of these samples in previously published papers [18-20].

The DRS measurements on bulk $\mathrm{Zn}_{0.95} \mathrm{TM}_{0.05} \mathrm{O}$ were performed in the ultraviolet-visible region (UV-Vis region) from $350 \mathrm{~nm}$ to $800 \mathrm{~nm}$ as it is the more appropriate method for the determination of absorption edges of powdered (colored and opaque) materials [21, 22]. Slightly thick samples were used to avoid accidental loss by partial transmission during the measurement of percent reflectance. The $\mathrm{Zn}_{0.95} \mathrm{TM}_{0.05} \mathrm{O}$ samples prepared by processing at high temperatures have bulk crystallites with size falling in the range of microns resulting in a considerably sharp fall in percent reflectance. Figures 4 (a) to 4(f) show the Diffuse Reflectance 


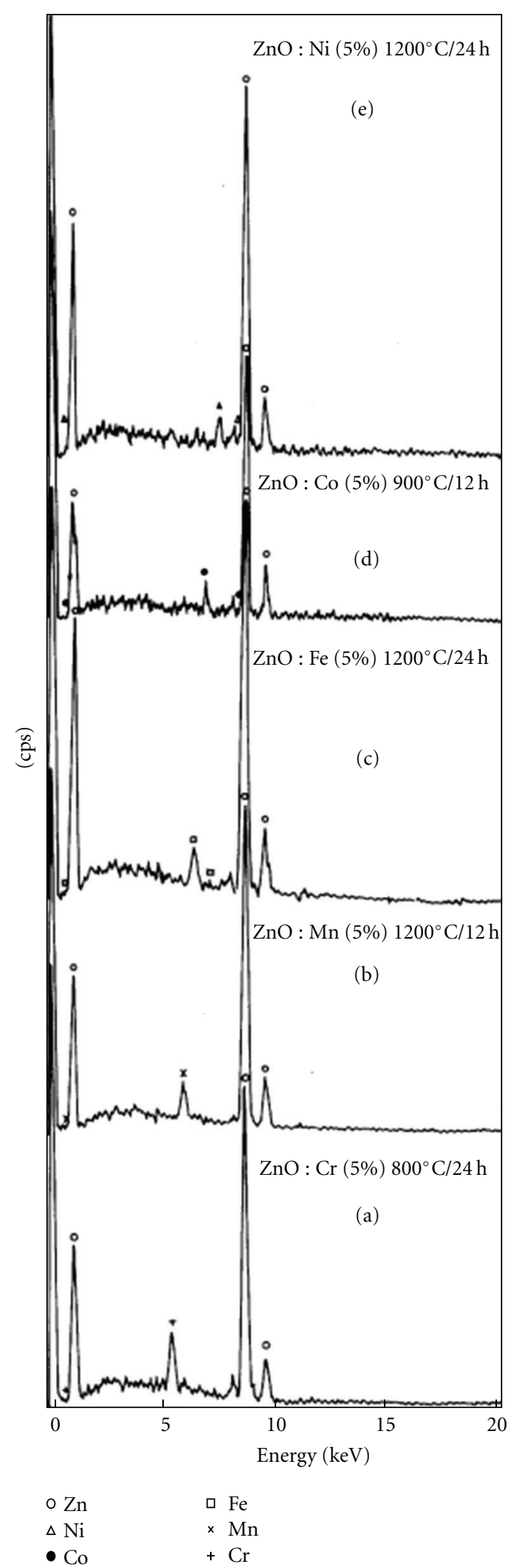

Figure 2: EDAX patterns of bulk $\mathrm{Zn}_{0.95} \mathrm{TM}_{0.05} \mathrm{O}(\mathrm{TM}=\mathrm{Cr}, \mathrm{Mn}, \mathrm{Fe}$, Co, \& Ni) samples (a-e).

Spectra (DRS) of $\mathrm{Zn}_{0.95} \mathrm{TM}_{0.05} \mathrm{O}$ compounds. The DRS of bulk $\mathrm{ZnO}$ shows sharp fall in reflectance corresponding to the absorption edge with maximum transparency in the visible region. All the $\mathrm{Zn}_{0.95} \mathrm{TM}_{0.05} \mathrm{O}$ compounds show a decrease in percent reflectance than pure bulk $\mathrm{ZnO}$ indicating dominant band gap excitations in the visible region. The reflectance edge of some of the $\mathrm{Zn}_{0.95} \mathrm{TM}_{0.05} \mathrm{O}$ samples shift towards the visible region indicating the band gap excitations by visible light (Figure 4(a)).

The increase in the diffuse reflectivity has a definite linear region of the greatest slope. This is attributed to an exponential drop in the absorption coefficient [21]. The onset of this exponential drop had been suggested as a more universal method of determining absorption edges from which the band gap can be deduced. A linear fit was given to the linear part of the increase in reflectivity for deducing the absorption edge. In case of two linear parts in the onset of increase in reflectance, the edge was determined from the intersection of the linear fit of the two linear portions [21]. The brilliant color of $\mathrm{Zn}_{0.95} \mathrm{TM}_{0.05} \mathrm{O}$ is the main feature. "Cr" doping in $\mathrm{ZnO}$ induced grayish brown color, red color for "Mn" doping, saffron for "Fe", bluish green for "Co," and green for "Ni" doping. The striking colors are attributed to interatomic transitions between the " $3 \mathrm{~d}$ " TM ions that are substituted at the cationic site of $\mathrm{ZnO}$.

The estimated band gap value of bulk $\mathrm{ZnO}$ is $3.37 \mathrm{eV}$. The spectrum of $\mathrm{Zn}_{0.95} \mathrm{Cr}_{0.05} \mathrm{O}$ has two linear parts, and the band gap value $2.96 \mathrm{eV}$ is deduced from the intersection of the two linear regions (Figure 4(b)). Red shift is observed on substitution with "Cr." Three absorption bands are observed between 475 and $750 \mathrm{~nm}$. These bands are due to electronic transitions in $\mathrm{Cr}^{3+}$. The transitions and the reflectance maxima correspond to the following transitions: ${ }^{4} \mathrm{~A}_{2}$ to ${ }^{4} \mathrm{~T}_{2}$ around $720 \mathrm{~nm},{ }^{4} \mathrm{~A}_{2}$ to ${ }^{4} \mathrm{~T}_{1}{ }^{(\mathrm{F})}$ around $625 \mathrm{~nm}$, and ${ }^{4} \mathrm{~A}_{2}$ to ${ }^{4} \mathrm{~T}_{1}{ }^{(\mathrm{P})}$ around $525 \mathrm{~nm}[23]$.

The band gap of $\mathrm{Zn}_{0.95} \mathrm{Mn}_{0.05} \mathrm{O}$ shows blue shift (Figure 4(c)) with a value of $3.42 \mathrm{eV}$, which is greater than pure $\mathrm{ZnO}$. This behavior agrees with the literature [24-26] values. The $\mathrm{Zn}_{0.95} \mathrm{Mn}_{0.05} \mathrm{O}$ sample is red in color, which is due to interatomic transitions between the divalent $\mathrm{Mn}^{2+}$ metal ions. The red color deepens with increasing sintering temperatures due to the increase in electron concentration by increase in $\mathrm{O}^{2-}$ vacancies. This feature is observed for all $\mathrm{Zn}_{0.95} \mathrm{TM}_{0.05} \mathrm{O}$ compounds. $\mathrm{Mn}^{2+}$ does not produce any reflectance maxima as it does not show crystal field splitting. The reflectance spectrum of $\mathrm{Zn}_{0.95} \mathrm{Fe}_{0.05} \mathrm{O}$ in Figure $4(\mathrm{~d}$ ) shows a shift towards lower energies, with a band gap value of $2.09 \mathrm{eV}$. This red shift is interpreted in terms of the sp-d exchange interaction between the band electrons and the localized "d" electrons of the transition metal ion at the cationic site [27]. Similar to $\mathrm{Mn}^{2+}, \mathrm{Fe}^{3+}$ also does not produce any reflectance maxima due to absence of crystal field splitting.

The reflectance spectrum of $\mathrm{Zn}_{0.95} \mathrm{Co}_{0.05} \mathrm{O}$ shows blue shift with a band gap value of $3.52 \mathrm{eV}$. The spectrum (Figure 4(e)) also shows $\mathrm{Co}^{2+}$ characteristic transitions in the visible region $[28,29]$ that imparts deep green color to the sample [26]. The series of reflectance maxima without much resolution are assigned to transition [23] from ${ }^{1} \mathrm{~A}_{1 \mathrm{~g}}$ ground state of $\mathrm{Co}^{3+}$. The reflectance spectrum of "Ni" doped $\mathrm{ZnO}$ shows red shift with a band gap value of 


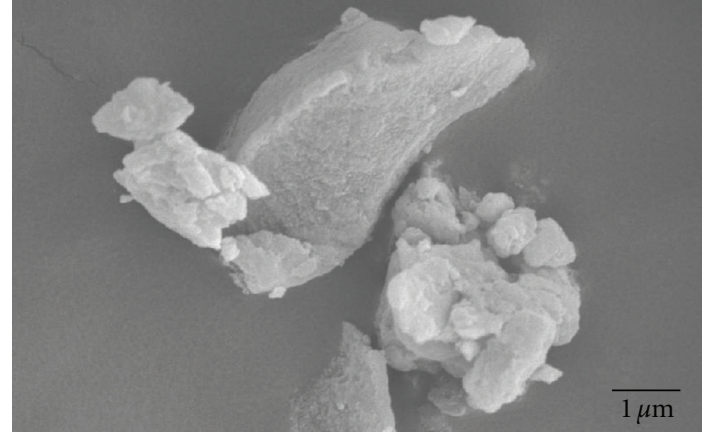

(a)

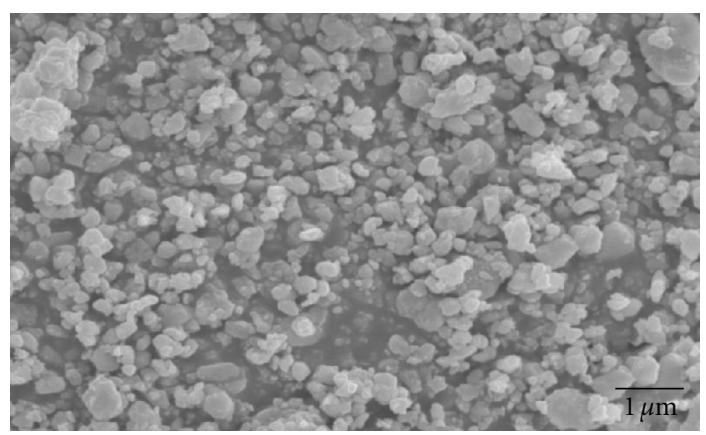

(c)

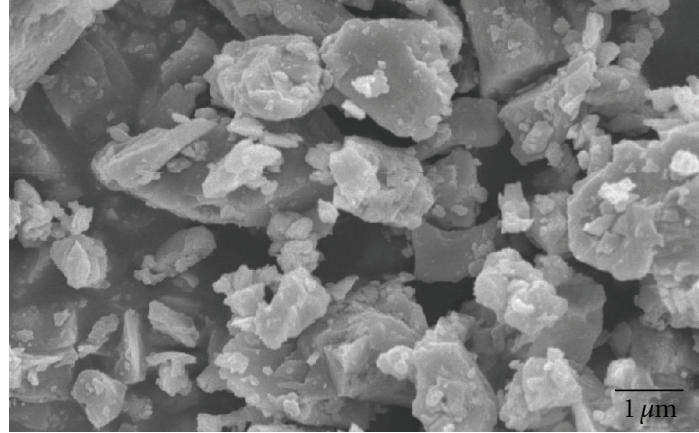

(b)

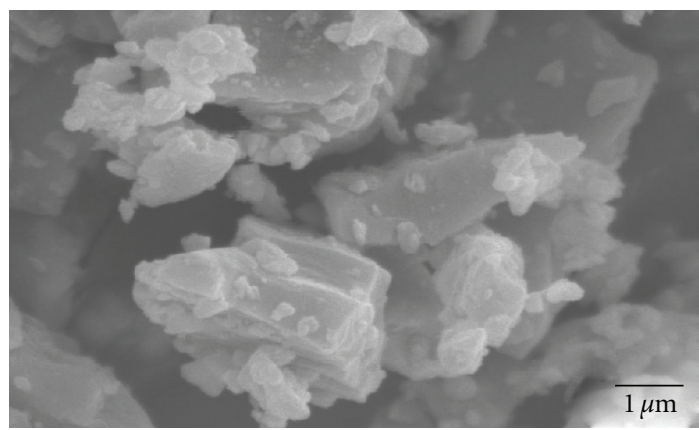

(d)

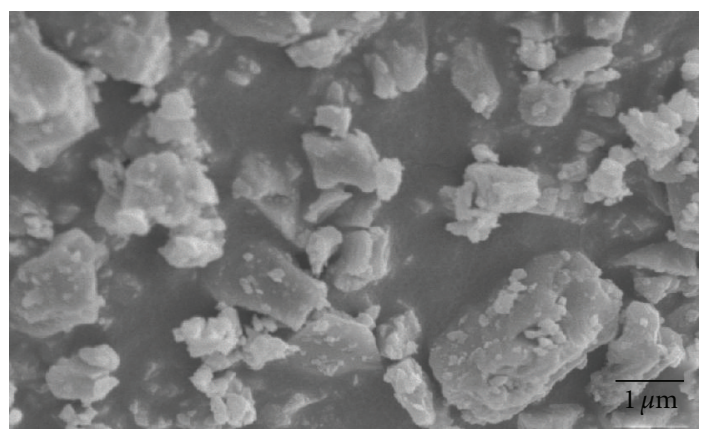

(e)

Figure 3: SEM micrographs of bulk $\mathrm{Zn}_{0.95} \mathrm{TM}_{0.05} \mathrm{O}(\mathrm{TM}=\mathrm{Cr}, \mathrm{Mn}, \mathrm{Fe}, \mathrm{Co}, \mathrm{\&} \mathrm{Ni})$ samples processed at various temperatures $((\mathrm{a}-\mathrm{e}))$.

$2.98 \mathrm{eV}$ (Figure 4(f)). $\mathrm{Ni}^{2+}$ in $\mathrm{ZnO}$ shows three reflectance maxima corresponding to the following transitions: ${ }^{3} \mathrm{~A}_{2 \mathrm{~g}}$ to ${ }^{3} \mathrm{~T}_{2 \mathrm{~g}}(585 \mathrm{~nm}),{ }^{3} \mathrm{~A}_{2 \mathrm{~g}}$ to ${ }^{3} \mathrm{~T}_{1 \mathrm{~g}}(545 \mathrm{~nm})$, and ${ }^{3} \mathrm{~A}_{2 \mathrm{~g}}$ to ${ }^{3} \mathrm{~T}_{1 \mathrm{~g}}{ }^{(\mathrm{P})}$ $(515 \mathrm{~nm})$ [23]. Thus bulk $\mathrm{ZnO}$ is found to present a different trend in variation of band-gap and brilliant colors on doping with " $3 \mathrm{~d}$ " TM ions. The representation of the variation of band gap of bulk $\mathrm{Zn}_{0.95} \mathrm{TM}_{0.05} \mathrm{O}(\mathrm{TM}=\mathrm{Cr}, \mathrm{Mn}, \mathrm{Fe}, \mathrm{Co}, \& \mathrm{Ni}$ ) samples with respect to the band gap of pure $\mathrm{ZnO}$ is shown in Figure 5. The samples which are single phase show blue shift, whereas the samples with secondary phases lie below the dotted line (Figure 5) indicating red shift. The offset towards red shift is higher compared to the offset towards blue region of the band gap with respect to pure $\mathrm{ZnO}$. This might be due to the coexistence of the secondary phases (Table 1) within the sample. Sernelius et al. [30] have discussed the theory of band gap widening and narrowing in Al-doped
$\mathrm{ZnO}$. The observation of red and blue shift in band gap of $\mathrm{Zn}_{0.95} \mathrm{TM}_{0.05} \mathrm{O}(\mathrm{TM}=\mathrm{Cr}, \mathrm{Mn}, \mathrm{Fe}, \mathrm{Co}, \& \mathrm{Ni})$ can be plausibly explained in analogy with $\mathrm{Al}$-doped $\mathrm{ZnO}$ [30]. The widening of band gap in case of heavily doped semiconductors is due to the blocking of the low-energy transitions by the donor electrons occupying the states at the bottom of the conduction band which is known as the Burstein-Moss effect.

$\mathrm{ZnO}$ being a "polar" semiconductor, there is a displacement of charge from one of the atomic species to the other, and hence the host atoms are charged. These moving charged particles cause a displacement polarization, wherein an electron in the conduction band forms a cloud of positive charge and the hole in valence band forms a cloud of negative charge around it. This particle and its charge cloud constitute a polaron which modifies the self-energy and cause a downward shift due to many-body interactions [30]. 


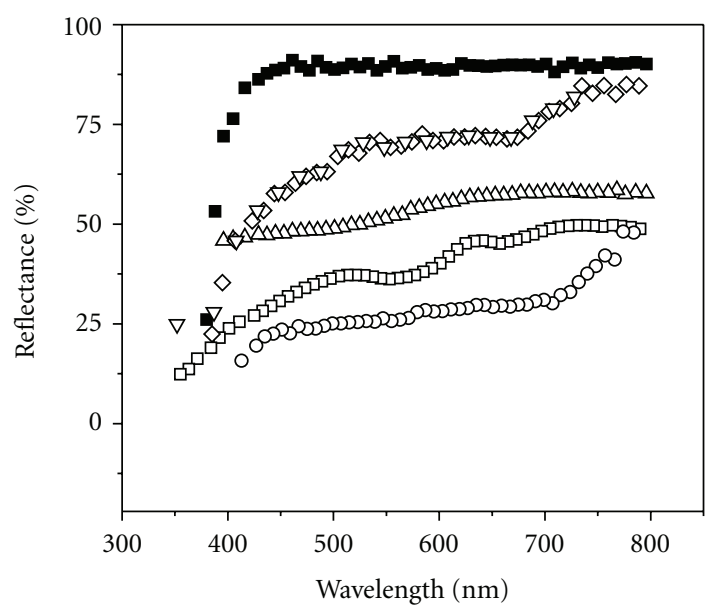

- Bulk $\mathrm{ZnO}$

$\mathrm{Zn}_{0.95} \mathrm{Cr}_{0.05} \mathrm{O}$

$\triangle \mathrm{Zn}_{0.95} \mathrm{Fe}_{0.05} \mathrm{O}$

○ $\mathrm{Zn}_{0.95} \mathrm{Mn}_{0.05} \mathrm{O}$

$\diamond \mathrm{Zn}_{0.95} \mathrm{Co}_{0.05} \mathrm{O}$

$\nabla \mathrm{Zn}_{0.95} \mathrm{Ni}_{0.05} \mathrm{O}$

(a)

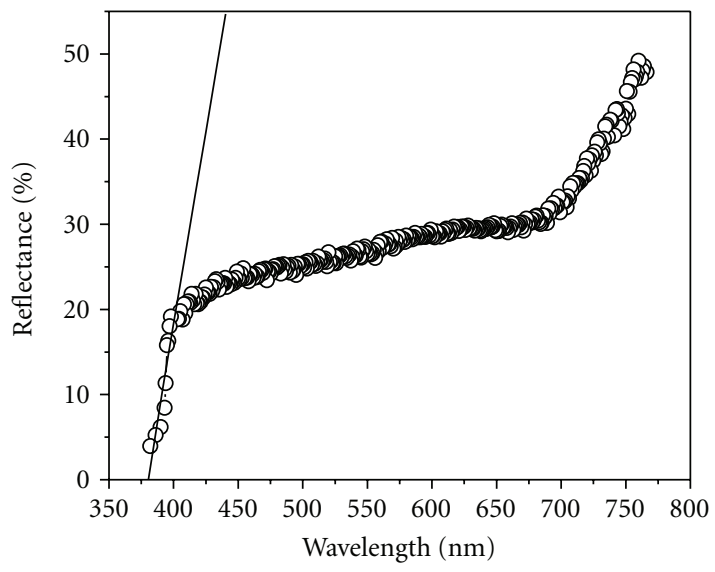

-O- Bulk $\mathrm{Zn}_{0.95} \mathrm{Mn}_{0.05} \mathrm{O}$

(c)

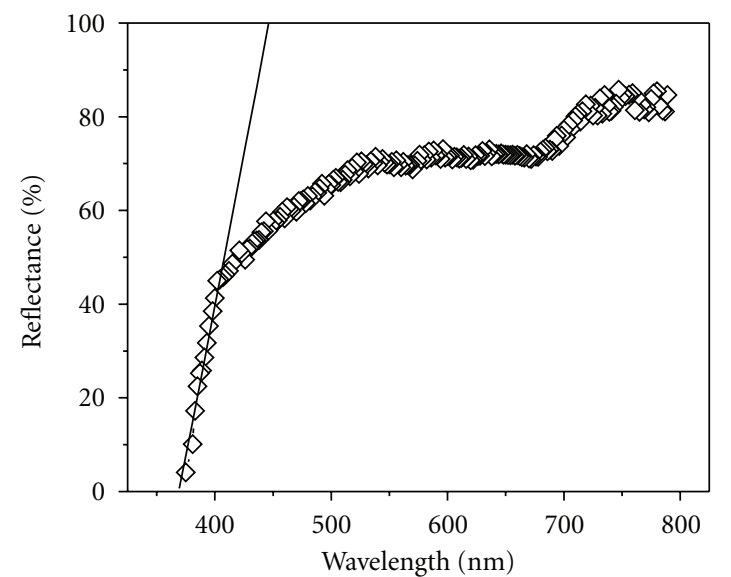

$\checkmark$ Bulk $\mathrm{Zn}_{0.95} \mathrm{Co}_{0.05} \mathrm{O}$

(e)

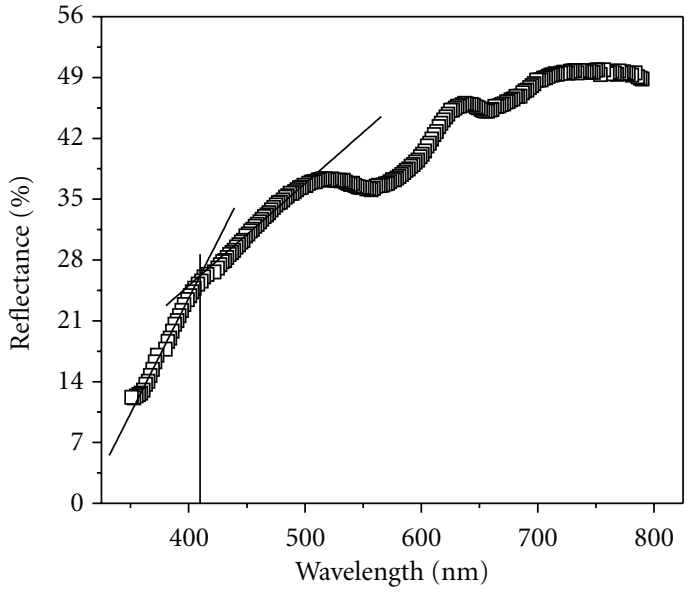

- - Bulk $\mathrm{Zn}_{0.95} \mathrm{Cr}_{0.05} \mathrm{O}$

(b)

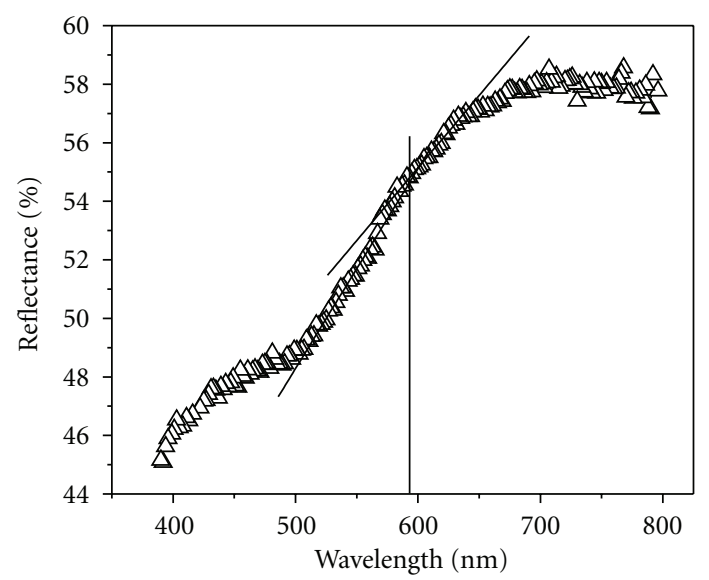

$-\triangle$ - Bulk $\mathrm{Zn}_{0.95} \mathrm{Fe}_{0.05} \mathrm{O}$

(d)

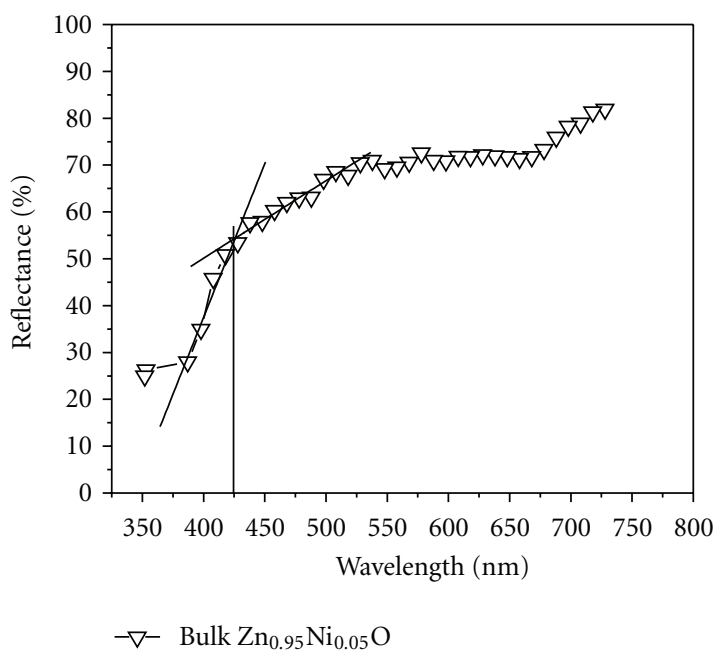

(f)

Figure 4: Diffuse Reflectance Spectrum of (a) bulk undoped $\mathrm{ZnO}$ in comparison with $\mathrm{Zn}_{0.95} \mathrm{TM}_{0.05} \mathrm{O}(\mathrm{TM}=\mathrm{Cr}, \mathrm{Mn}, \mathrm{Fe}, \mathrm{Co}$, \& $\mathrm{Ni}$ ) samples and ((b-f)) bulk $\mathrm{Zn}_{0.95} \mathrm{TM}_{0.05} \mathrm{O}(\mathrm{TM}=\mathrm{Cr}, \mathrm{Mn}, \mathrm{Fe}, \mathrm{Co}, \& \mathrm{Ni})$ samples. 


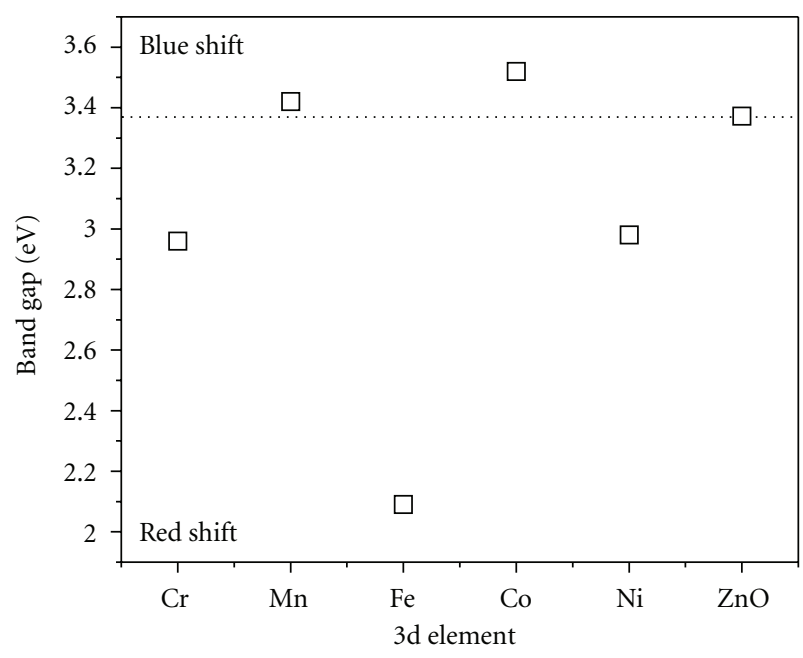

Figure 5: Variation in band gap as a function of the dopants. The dotted line is guide for the eyes. The values lying above and below the dotted line indicate blue and red shift in band gap, respectively, with respect to the host $\mathrm{ZnO}$.

In a "nonpolar" semiconductor, due to the electrons of equal spin avoiding each other due to statistical reasons and coulomb repulsion and by the doped impurities, the electrons are surrounded by excess of holes thereby lowering its energy leading to downward shift of the conduction band along with a distortion in band structure and band tailing. Also, the holes in the valence band are repelled by the positively charged donor ions and have a tendency to avoid them thereby causing a shift in their energy [30]. All these effects shift the valence band towards the conduction band and the conduction band edge towards the valence band ultimately leading to the narrowing of the band gap. Thus the red and blue shift of band gap of " $3 \mathrm{~d}$ " transition metal ion-doped $\mathrm{ZnO}$ into the visible and UV region extends the possibility of $\mathrm{ZnO}$ to be tailor-made for applications in the UV-Vis region.

\section{Conclusion}

Blue and red shifts in the band gap of TM ion-doped $\mathrm{ZnO}$ prepared by ceramic method were observed from the onset of the linear increase of the diffuse reflectivity spectrum. The estimated values of band gap need to be correlated with extended systematic experimental results so as to precisely tune the band gap of $\mathrm{ZnO}$ for a specific application by varying the composition of each of the substitutionally doped $3 \mathrm{~d}$ transition metal ions at the cationic site. The observed variation in band gap is pertained to the experimental conditions and samples described here. A systematic study on the composition (from lower to higher value) of each of the dopant would yield a trend for the entire range of composition using in which the TM-doped $\mathrm{ZnO}$ compounds could be exploited for magneto-optical device applications.

\section{Acknowledgments}

The authors thank Professor Dr. M. Palanichamy, Department of Chemistry, Anna University for fruitful discussions.
The author D. P. Joseph thanks the CSIR, Government of India for the support of this work by the award of Senior Research Fellowship, 2007.

\section{References}

[1] A. Ohtomo, K. Tamura, M. Kawasaki et al., "Room-temperature stimulated emission of excitons in $\mathrm{ZnO} /(\mathrm{Mg}, \mathrm{Zn}) \mathrm{O}$ superlattices," Applied Physics Letters, vol. 77, no. 14, pp. 2204-2206, 2000.

[2] Y. Z. Yoo, T. Fukumura, Z. Jin et al., "ZnO-CoO solid solution thin films," Journal of Applied Physics, vol. 90, no. 8, pp. 42464250, 2001.

[3] H. Ohno, "Making nonmagnetic semiconductors ferromagnetic," Science, vol. 281, no. 5379, pp. 951-956, 1998.

[4] K. Sato and H. Katayama-Yoshida, "Material design for transparent ferromagnets with $\mathrm{ZnO}$-based magnetic semiconductors," Japanese Journal of Applied Physics, vol. 39, no. 6B, pp. L555-L558, 2000.

[5] H. Katayama-Yoshida and K. Sato, "Materials design for semiconductor spintronics by ab initio electronic-structure calculation," Physica B, vol. 327, no. 2-4, pp. 337-343, 2003.

[6] S. A. Wolf, D. D. Awschalom, R. A. Buhrman et al., "Spintronics: a spin-based electronics vision for the future," Science, vol. 294, no. 5546, pp. 1488-1495, 2001.

[7] T. Dietl, "Ferromagnetic semiconductors," Semiconductor Science and Technology, vol. 17, no. 4, pp. 377-392, 2002.

[8] M. Toyoda, H. Akai, K. Sato, and H. Katayama-Yoshida, "Electronic structures of (Zn, TM)O (TM: V, Cr, Mn, Fe, Co, and Ni) in the self-interaction-corrected calculations," Physica B, vol. 376-377, no. 1, pp. 647-650, 2006.

[9] T. Fukushima, K. Sato, H. Katayama-Yoshida, and P. H. Dederichs, "Spinodal decomposition under layer by layer growth condition and high curie temperature quasi-one-dimensional nano-structure in dilute magnetic semiconductors," Japanese Journal of Applied Physics, vol. 45, no. 12-16, pp. L416-L418, 2006.

[10] H. Katayama-Yoshida, K. Sato, T. Fukushima et al., "Theory of ferromagnetic semiconductors," Physica Status Solidi A, vol. 204, no. 1, pp. 15-32, 2007.

[11] K. Sato, T. Fukushima, and H. Katayama-Yoshida, "Superparamagnetic blocking phenomena and room-temperature ferromagnetism in wide band-gap dilute magnetic semiconductor (Ga, Mn)N," Japanese Journal of Applied Physics, vol. 46, no. 25-28, pp. L682-L684, 2007.

[12] S. J. Pearton, C. R. Abernathy, G. T. Thaler et al., "Wide bandgap GaN-based semiconductors for spintronics," Journal of Physics: Condensed Matter, vol. 16, no. 7, pp. R209-R245, 2004.

[13] K. Ando, H. Saito, Z. Jin et al., "Magneto-optical properties of $\mathrm{ZnO}$-based diluted magnetic semiconductors," Journal of Applied Physics, vol. 89, no. 11, pp. 7284-7286, 2001.

[14] W. Prellier, A. Fouchet, and B. Mercey, "Oxide-diluted magnetic semiconductors: a review of the experimental status," Journal of Physics Condensed Matter, vol. 15, no. 37, pp. R1583-R1601, 2003.

[15] S. J. Pearton, D. P. Norton, K. Ip, Y. W. Heo, and T. Steiner, "Recent progress in processing and properties of $\mathrm{ZnO}$," Progress in Materials Science, vol. 50, no. 3, pp. 293-340, 2005.

[16] L. Lutterotti, "Materials Analysis Using Diffraction (MAUD) version: 2.072," 2008, http://www.ing.unitn.it/ maud/. 
[17] D. P. Joseph, Analysis of $3 d$ transition elements doped $\mathrm{ZnO}, \mathrm{CuO}$ and $\mathrm{Cu}-\mathrm{Zn}$-Se diluted magnetic semiconductors, Ph.D. thesis, University of Madras, Chennai, India, May 2009.

[18] D. P. Joseph, G. S. Kumar, and C. Venkateswaran, "Structural, magnetic and optical studies of $\mathrm{Zn}_{0.95} \mathrm{Mn}_{0.05} \mathrm{O}$ DMS," Materials Letters, vol. 59, no. 21, pp. 2720-2724, 2005.

[19] D. P. Joseph, S. Ayyappan, and C. Venkateswaran, "Comparative studies on $\mathrm{Zn}_{0.95} \mathrm{Ni}_{0.05} \mathrm{O}$ DMS synthesized by coprecipitation and ceramic methods," Journal of Alloys and Compounds, vol. 415, no. 1-2, pp. 225-228, 2006.

[20] D. P. Joseph, S. Naveenkumar, N. Sivakumar, and C. Venkateswaran, "Synthesis of $\mathrm{Zn}_{0.95} \mathrm{Cr}_{0.05} \mathrm{O}$ DMS by coprecipitation and ceramic methods: structural and magnetization studies," Materials Chemistry and Physics, vol. 97, no. 1, pp. 188-192, 2006.

[21] P. D. Fochs, "The measurement of the energy gap of semiconductors from their diffuse reflection spectra," Proceedings of the Physical Society. Section B, vol. 69, no. 1, p. 70, 1955.

[22] T. Nguyena and A. R. Hind, "The measurement of absorption edge and band gap properties of novel nanocomposite materials," Varian Cary 500 Spectrophotometer manual No. 081, http://www.chem.agilent.com/Library/applications/uv81.pdf.

[23] F. A. Cotton and G. Wilkinson, Advanced Inorganic Chemistry, chapter 3, Wiley Eastern Private, Singapore, 5th edition, 1988.

[24] A. Tiwari, C. Jin, A. Kvit, D. Kumar, J. F. Muth, and J. Narayan, "Structural, optical and magnetic properties of diluted magnetic semiconducting $\mathrm{Zn}_{1-x} \mathrm{Mn}_{x} \mathrm{O}$ films," Solid State Communications, vol. 121, no. 6-7, pp. 371-374, 2002.

[25] A. Wójcik, K. Kopalko, M. Godlewski et al., "Monocrystalline and polycrystalline $\mathrm{ZnO}$ and $\mathrm{ZnMnO}$ films grown by atomic layer epitaxy-growth and characterization," Acta Physica Polonica A, vol. 105, no. 6, pp. 667-673, 2004.

[26] M. H. Kane, K. Shalini, C. J. Summers et al., "Magnetic properties of bulk $\mathrm{Zn}_{1-x} \mathrm{Mn}_{x} \mathrm{O}$ and $\mathrm{Zn}_{1-x} \mathrm{Co}_{x} \mathrm{O}$ single crystals," Journal of Applied Physics, vol. 97, no. 2, Article ID 023906, 2005.

[27] K. J. Kim and Y. R. Park, "Optical investigation of $\mathrm{Zn}_{1-x} \mathrm{Fe}_{x} \mathrm{O}$ films grown on $\mathrm{Al}_{2} \mathrm{O}_{3}(0001)$ by radio-frequency sputtering," Journal of Applied Physics, vol. 96, no. 8, pp. 4150-4153, 2004.

[28] S. Ramachandran, A. Tiwari, and J. Narayan, " $\mathrm{Zn}_{0.9} \mathrm{Co}_{0.1} \mathrm{O}-$ based diluted magnetic semiconducting thin films," Applied Physics Letters, vol. 84, no. 25, pp. 5255-5257, 2004.

[29] J. H. Kim, H. Kim, D. Kim, S. G. Yoon, and W. K. Choo, "Optical and magnetic properties of laser-deposited Co-doped ZnO thin films," Solid State Communications, vol. 131, no. 11, pp. 677-680, 2004.

[30] B. E. Sernelius, K. F. Berggren, Z. C. Jin, I. Hamberg, and C. G. Granqvist, "Band-gap tailoring of $\mathrm{ZnO}$ by means of heavy $\mathrm{Al}$ doping," Physical Review B, vol. 37, no. 17, pp. 10244-10248, 1988. 

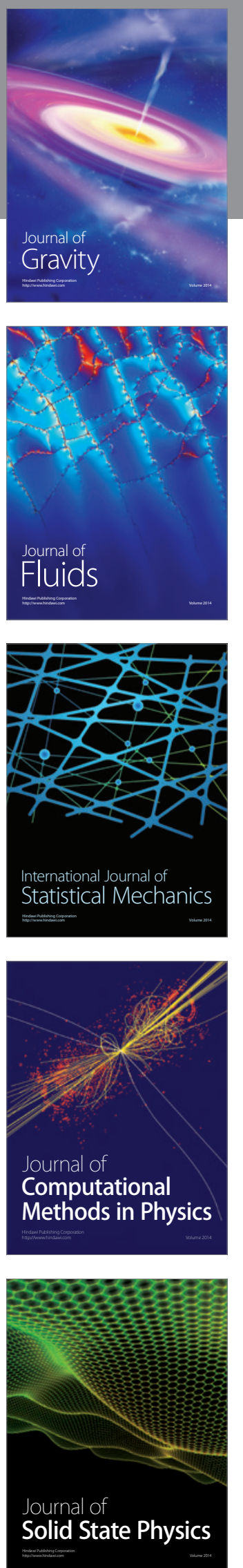

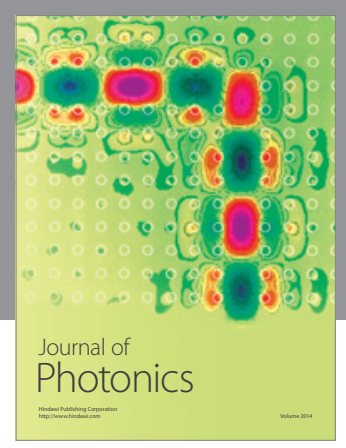

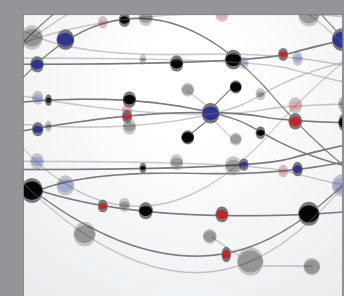

The Scientific World Journal
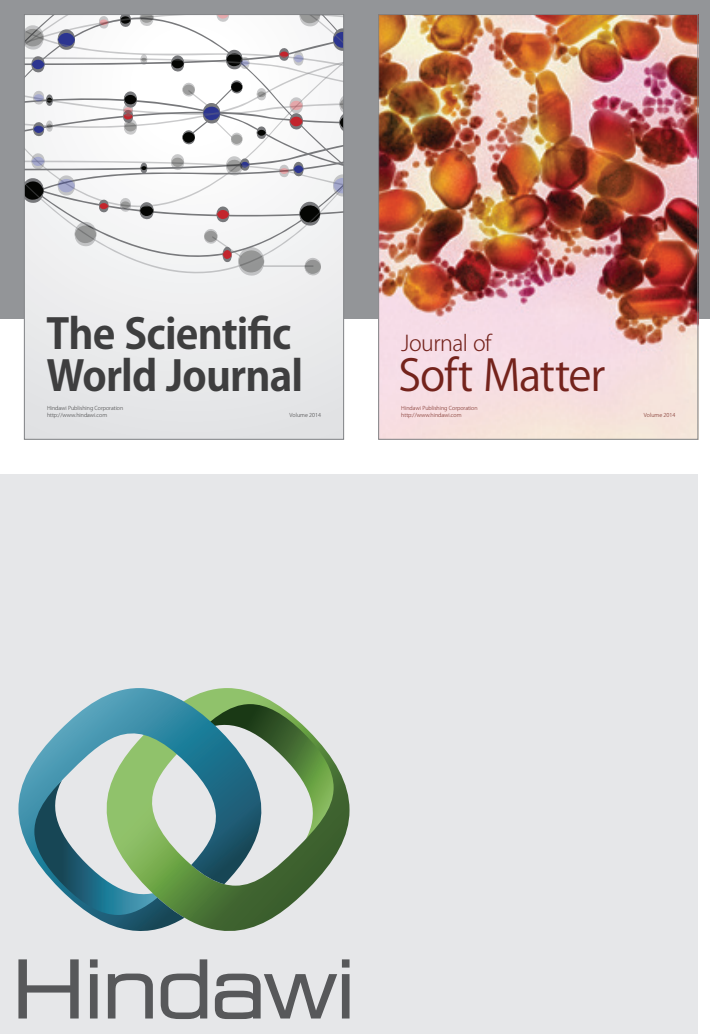

Submit your manuscripts at

http://www.hindawi.com
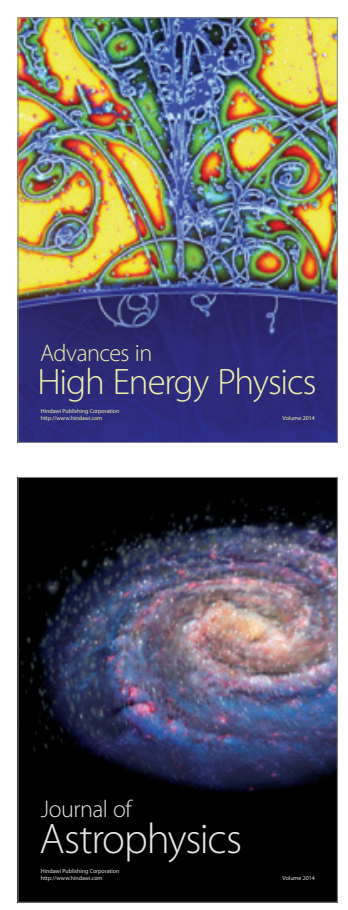
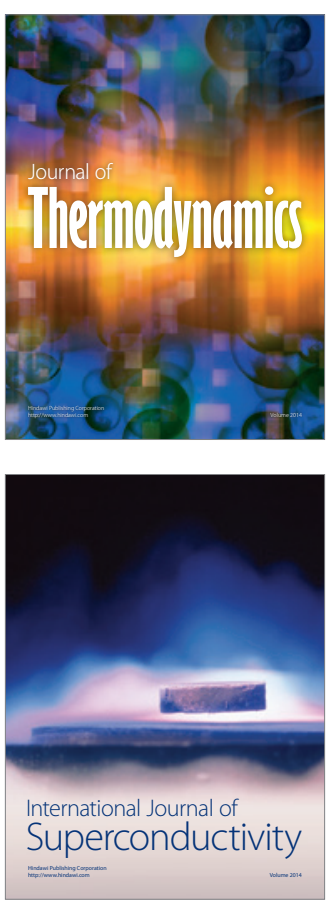
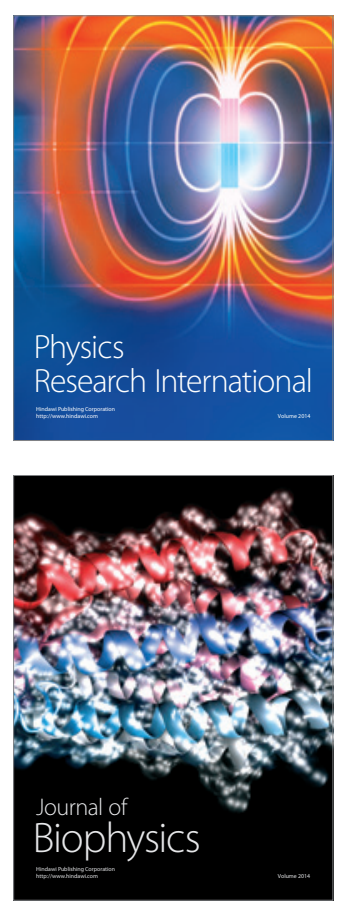
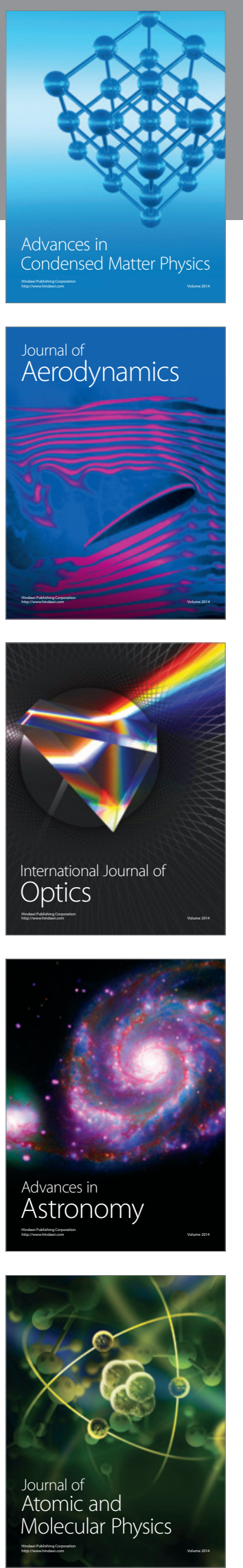